\title{
DETAILS OF MAGNETIC POLARITY TRANSITIONS RECORDED IN A HIGH DEPOSITION RATE DEEP-SEA CORE*
}

\author{
N.D. OPDYKE, D.V. KENT and W. LOWRIE \\ Lamont-Doherty Geological Observatory of Columbia University \\ Palisades, New York 10964 (USA)
}

Received 1 August 1973

Revised version received 23 October 1973

\begin{abstract}
Measurements of the NRM of a $26 \mathrm{~m}$ long deep-sea core from the southern Indian Ocean indicated the presence of three transitions of magnetic polarity which have been identified as the upper and lower Jaramillo and the upper Olduvai on the basis of micropaleontological criteria. Detailed studies of the magnetic reversals were made in view of the high deposition rates $\left(\sim 9 \mathrm{~cm} / 10^{3} \mathrm{yr}\right)$ present over sections of the core.

The NRM was found stable against alternating fields. Magnetic mineralogy studies indicated the presence of titanomagnetite and magnetite which probably have not undergone any significant low-temperature oxidation.

The three polarity changes had the following features in common: (1) presence of intermediate directions of magnetization; (2) a pronounced drop in the intensity of magnetization; (3) the drop in intensity of magnetization was coincident with the large directional fluctuations. Measurements of saturation isothermal and anhysteretic remanence, and bulk susceptibility, show that the decrease in NRM intensity associated with each polarity change is not due to a low concentration of the magnetic minerals. The best estimate for the duration of a polarity transition is approximately $4600 \mathrm{yr}$.

There is evidence for both eastward and westward drift of the non-dipole field, which appears to be dominant during the polarity transition interval. The data presented here support a model of a reversing field in which the main dipole field decays to a low value and then builds up in the opposite direction.
\end{abstract}

\section{Introduction}

During the 14th cruise of the RV "Robert Conrad" the longest piston core ever taken from a LamontDoherty research vessel (RC14-14) was raised from the Crozet basin at latitude $35^{\circ} 55^{\prime} \mathrm{S}$, longitude $59^{\circ} 58^{\prime} \mathrm{E}$ in a water depth of $4916 \mathrm{~m}$. The true core length after removal of flow-in was $2588 \mathrm{~cm}$. The relative azimuthal orientation of the core was preserved by scribing a continuous line on the surface of the sediment during extrusion. Although this line had an arbitrary azimuth, it made relative declination studies possible for this core along with inclination observations. This orientation method has been frequently used for magnetic declination studies in low latitude cores [1].

\footnotetext{
* L-DGO Contribution No. 2007.
}

The core consists of radiolarian and diatom lutite, burrow mottled in some portions and faintly laminated in others. The $3.5 \mathrm{-kHz}$ profiler records taken near the core site show a series of asymmetric reflection hyperbolas indicating a possible dune-type morphology. Bottom photographs show a mud surface with no visible indications of scouring.

\section{Magnetic mineralogy}

A concentration of ferromagnetic grains was obtained from a sample near the bottom of core RC14-14 using a technique similar to that described by Løvlie et al. [2]. The extracted magnetic fraction consisted predominantly of dark colored grains, although some lighter colored grains were also present. High field (4 kOe) Curie temperature analysis was 


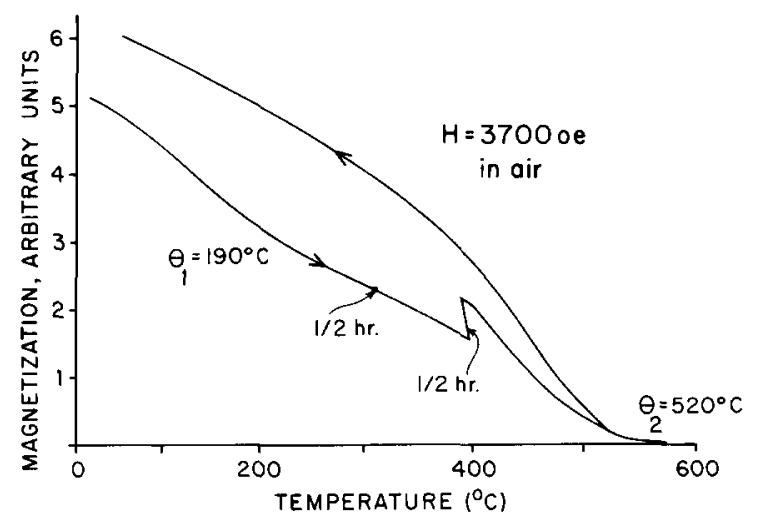

Fig. 1. Thermomagnetic curve for magnetic separate from bottom of core RC14-14. Sample was brought quickly to $300^{\circ} \mathrm{C}$ and then to $400^{\circ} \mathrm{C}$, held at each temperature for $\frac{1}{2} \mathrm{hr}$, before completion of heating and then cooling half of thermal cycle.

performed on the extract in order to identify the magnetic minerals.

The sample was heated rapidly in air to $300^{\circ} \mathrm{C}$ and maintained at that temperature for one half hour. The temperature was raised to $400^{\circ} \mathrm{C}$ and maintained for an additional half hour. It was then raised quickly to about $600^{\circ} \mathrm{C}$, and the sample was allowed to cool to room temperature.

The thermomagnetic curve was irreversible (fig. 1). Initially the'magnetic extraction contained two phases, one of which has a low Curie temperature around $190^{\circ} \mathrm{C}$. Although no change in saturation magnetization was observed during the $300^{\circ} \mathrm{C}$ heat treatment, during the half hour at $400^{\circ} \mathrm{C}$ there was a substantial increase. The second magnetic phase had a Curie temperature of $520^{\circ} \mathrm{C}$. During the cooling half of the thermal cycle a single Curie temperature of $520^{\circ} \mathrm{C}$ was observed, and there was an increase in saturation magnetization over the initial value.

The $520^{\circ} \mathrm{C}$ Curie temperature probably indicates a magnetite with a low titanium content. For this mineral, using the general titanomagnetite formula $x \mathrm{Fe}_{2} \mathrm{TiO}_{4}(1-x) \mathrm{Fe}_{3} \mathrm{O}_{4}$ the value of the compositional parameter $(x)$ would be 0.10 [3]. The second of the initial phases, with the $190^{\circ} \mathrm{C}$ Curie temperature, may have been either a titanomagnetite (with $x$ equal to 0.53 ) or a titanomaghemite. On heating in air at elevated temperatures, these minerals unmix to give a titanium-rich phase and a titanium-poor phase whose saturation magnetization is greater than that of the original phase, accounting for the increase in magnetization on cooling to room temperature [4].

Due to the lower activation energy for unmixing of titanomaghemite compared to that for cation migration in a titanomagnetite $[5,6]$, unmixing of the former can proceed at lower temperatures. Because no significant effect was observed in our thermomagnetic analysis at $300^{\circ} \mathrm{C}$, and only a slow change at $400^{\circ} \mathrm{C}$, it is probable that the initial magnetic minerals in this core were essentially magnetite and titanomagnetite. The results of these considerations lead us to believe that secondary components of magnetization resulting from low-temperature oxidation are likely to be unimportant in this core.

\section{Magnetic stratigraphy}

Specimens were chosen from eight levels through the core for detailed studies of directional and intensity changes with increasing alternating fields. The equipment used was similar to that described by McElhinny [7]. The resulting AF demagnetization curves and directions of magnetization are shown in fig. 2 for normally and reversely magnetized specimens, and in fig. 3 for specimens with intermediate directions. The results indicated good magnetic stability throughout the core with the median destructive field being in all cases above $100 \mathrm{Oe}$ and in most cases around $200 \mathrm{Oe}$. Directional changes in peak fields higher than 100 Oe were usually within the measurement error. A demagnetization field of $100 \mathrm{Oe}$ was chosen for blanket treatment of the core.

Over most of the core, samples were taken at $10-\mathrm{cm}$ intervals. The direction and intensity of the remanence after treatment in the 100-Oe alternating field were measured for all samples. In this way, the magnetic polarity boundaries were located. The sections of the core containing these polarity transitions were then sampled as continuously as possible in an attempt to study the behavior of the geomagnetic field as the polarity transitions took place. The observed variations of declination, inclination and intensity in the core are shown in fig. 4 . The consistency of the data was high, and the magnetization direction changed by $180^{\circ}$ across each polarity change 

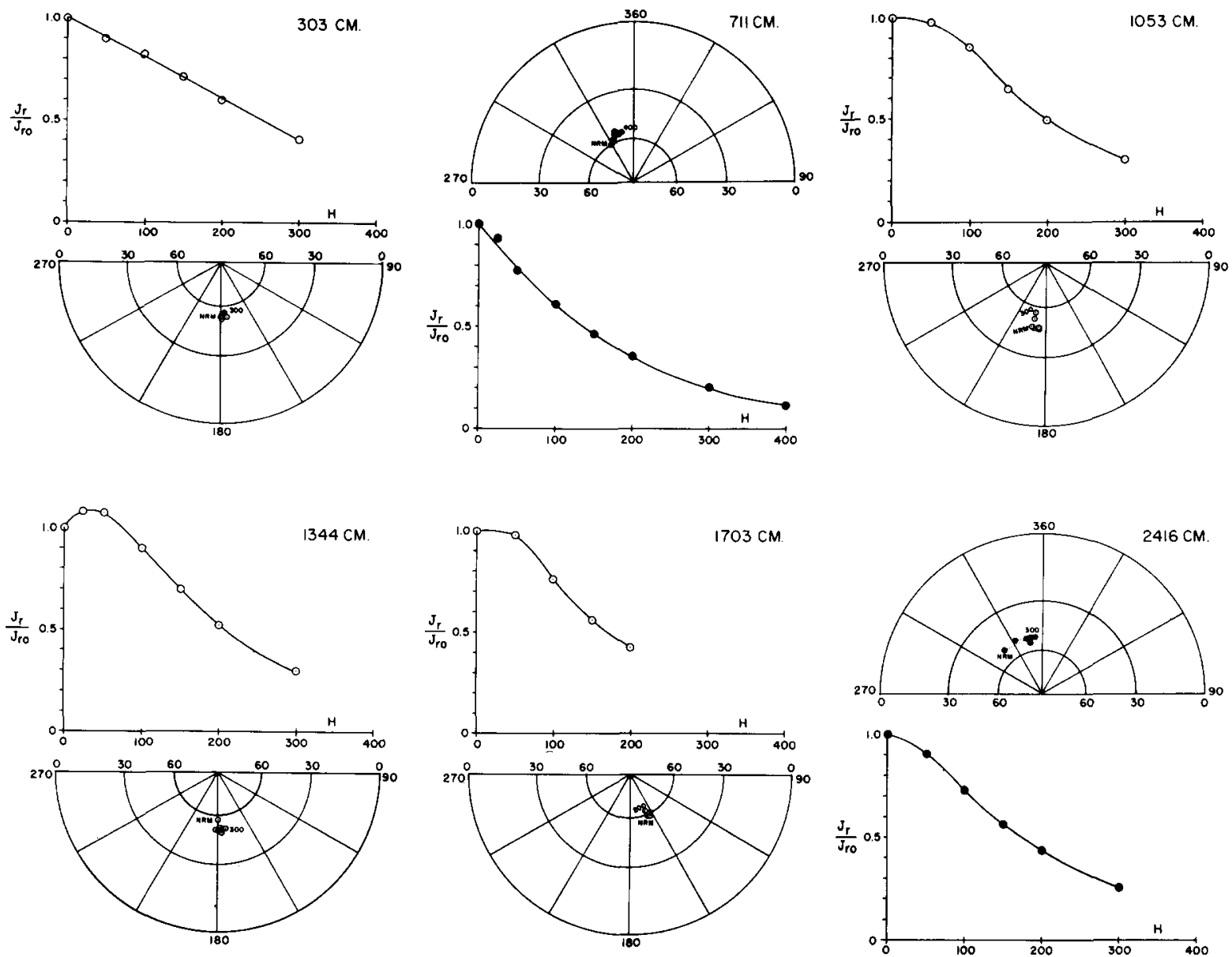

Fig. 2. Variation of NRM intensity and direction with partial demagnetization by alternating fields of six specimens. Specimens from $711 \mathrm{~cm}$ and $2416 \mathrm{~cm}$ are normally magnetized (negative inclinations); the remaining four specimens are reversely magnetized (positive inclinations).
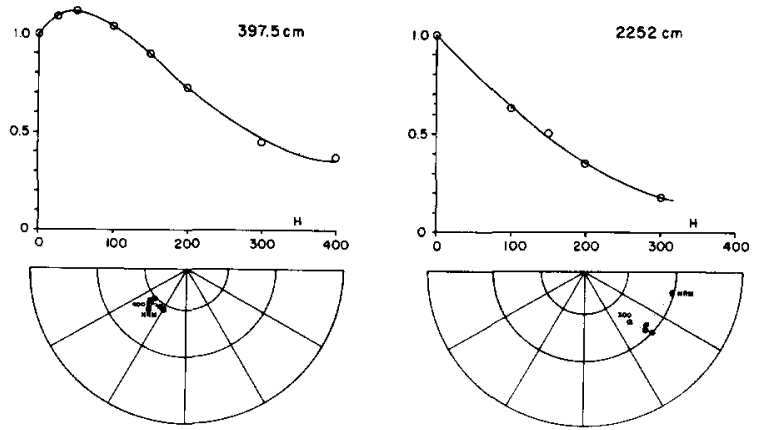

Fig. 3. Variation of NRM intensity and direction with partial demagnetization by alternating fields of two specimens with intermediate directions. Both specimens have positive inclinations.
The average inclination in the normally magnetized section of the core was $-56.5^{\circ}$ (s.d. $\left.=8.7^{\circ}\right)$; in the reversed section of the core the mean inclination was $58.6^{\circ}$ (s.d. $=6.7^{\circ}$ ). The absolute values were not significantly different from each other or from the inclination of the axial dipole field at the site, which was $55.5^{\circ}$.

It can be seen immediately from fig. 4 that, although the top of the core is somewhat disturbed, it is clearly reversely magnetized to a depth of 460 $\mathrm{cm}$. A normal interval follows from 460 to $940 \mathrm{~cm}$. Then there is a long unbroken stretch of reversely magnetized core to a depth of $2250 \mathrm{~cm}$ where a polarity change again occurs. The remainder of the core is normally magnetized. Each polarity transi- 

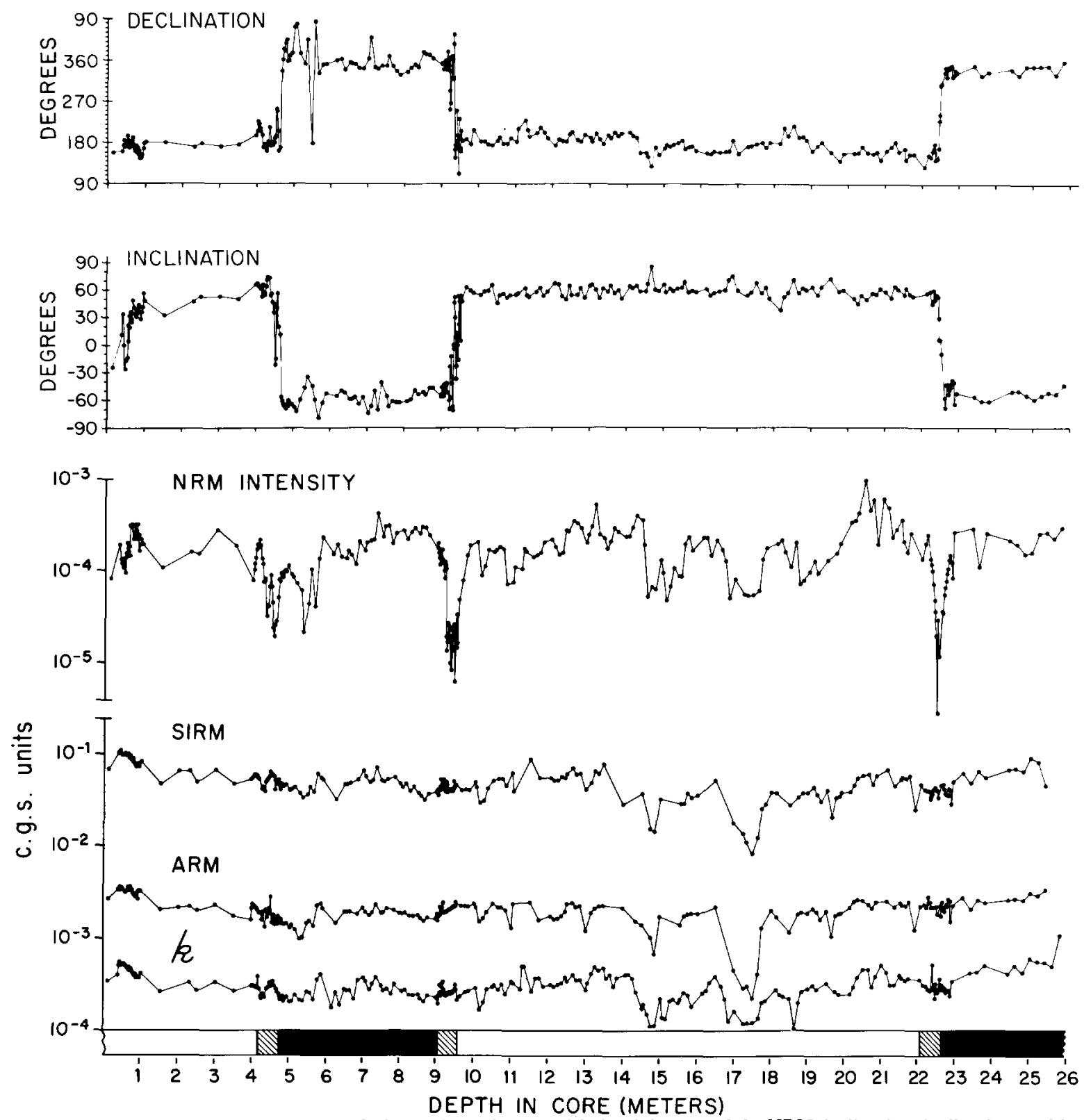

Fig. 4. Magnetic characteristics of core RC14-14. The variations with depth in core of the NRM declination, inclination, and intensity as well as the intensity of SIRM and ARM (see text for explanation) are the values after an alternating field treatment of 100 Oe. The variation of bulk susceptibility $(k)$ is also shown. Bar scale at bottom shows interpretation of NRM directional data: black is normal, white reversed and hachured is intermediate magnetization.

tion is characterized by a distinct drop of remanent intensity.

The magnetic stratigraphy is not obvious since no Brunhes age sedimensts are present at the top of the core which consequently must be older than 690,000 yr. Dr. J.D. Hays (personal communication) has identified the polarity transition at $2250 \mathrm{~cm}$ as the upper Olduvai reversal on the basis of the extinction 
of Clathrocylas bicornus [8,9]. The only prominent normal interval above this point in the magnetic time scale is the Jaramillo event. We, therefore, correlate the normal interval between 460 and $930 \mathrm{~cm}$ with the Jaramillo event.

The duration of the Jaramillo event has been estimated by Opdyke [10] to be 56,000 yr. This would make the rate of sedimentation within the Jaramillo event $8.6 \mathrm{~cm} / 1000 \mathrm{yr}$, in this core. Clearly, this high rate of sedimentation did not persist for long because if it did the Olduvai event could not have been penetrated. It is evident that a hiatus is present somewhere between the bottom of the Jaramillo and the top of the Olduvai, although there is no obvious lithological break that would indicate its position. The sedimentological conditions which cause a situation where high rates of sedimentation alternate with apparent nondeposition are not at present understood but they are under active investigation. It is apparent, from other cores in the region, however, that the hiatuses inferred in this core are not of regional extent.

\section{Intensity changes}

It has been shown previously [11] that reversals of polarity in cores are characterized by a sharp decrease in remanent intensity in the transition zones. This is seen clearly in RC14-14 as shown in fig. 4. In most cores, the rates of sedimentation are so low that intermediate directions, which are often in lava sequences, are seldom seen. Because of the high deposition rate of RC14-14, intermediate directions of magnetization are present within each transition interval as well as a sharp decrease in intensity.

A decrease in the intensity of magnetization can be due to: (a) less effective magnetic alignment resulting from a decrease in the strength of the magnetizing field; (b) a cancellation effect due to oppositely aligned fractions within the same sample [12]; or (c) a decrease in the amount of magnetic material present in the core. Possibility (b) can probably be ruled out in RC14-14 because of the number of adjacent samples in which reduced intensity was observed. In order to test for the possibility (c), bulk susceptibility $(k)$, anhysteretic remanent magnetization (ARM) and saturation isothermal remanent magnetization (SIRM) measurements were made on all samples. The results are shown in fig. 4. Each remanent intensity was measured after AF treatment in a field of $100 \mathrm{Oe}$ as for the NRM.

The bulk susceptibility was measured on a commercial susceptibility bridge with an accuracy of $5 \%$. The mean value of $k$ for 384 samples was $3.1 \times 10^{-4}$ gauss/Oe with a standard deviation of $1.05 \times 10^{-4}$.

The SIRM was produced by magnetizing the specimens in a field of 8000 Oe with a 4-inch electromagnet. The ARM was producedusing an alternating field of 1200 Oe coaxial with a constant field of 1 Oe.

From an inspection of fig. 4 , it can be seen that $k$, SIRM and ARM give an internally coherent picture of the variation of the magnetic mineral concentration throughout the length of the core. For instance, between 17 and $18 \mathrm{~m}$ a decided drop in all three parameters occurs. This feature is more pronounced in the ARM and SIRM than in the susceptibility. A similar drop intensity of the NRM is also observed showing clearly the influence on intensity of a magnetic mineralogy variation. The greatest reductions in NRM intensity, however, occur at the positions of changes of magnetic polarity. At none of these polarity transitions is there a corresponding drop in $k$, ARM or SIRM intensity. This strongly indicates that the drop of NRM intensity at these points is due to a decrease in the strength of the earth's magnetic field, during the time required for the polarity transition to take place.

\section{Details of polarity transitions}

In order to examine in detail the changing polarity of the field, the declination, inclination and intensity have been plotted in fig. 5 on an expanded scale. Well-defined intermediate directions of magnetization are present in all three transitions. However, it appears that the most detailed record of a polarity change is recorded in the lower Jaramillo reversa!. The reversals which occur at the upper Jaramillo/ Matuyama and Olduvai/Matuyama boundaries occur in sediments which show evidence of bioturbation. The bioturbation may well have acted to smooth out these transition zones so obscuring the details of the reversals. The Matuyama/Jaramillo transition; on the other hand, fortunately occurs in sediments which 


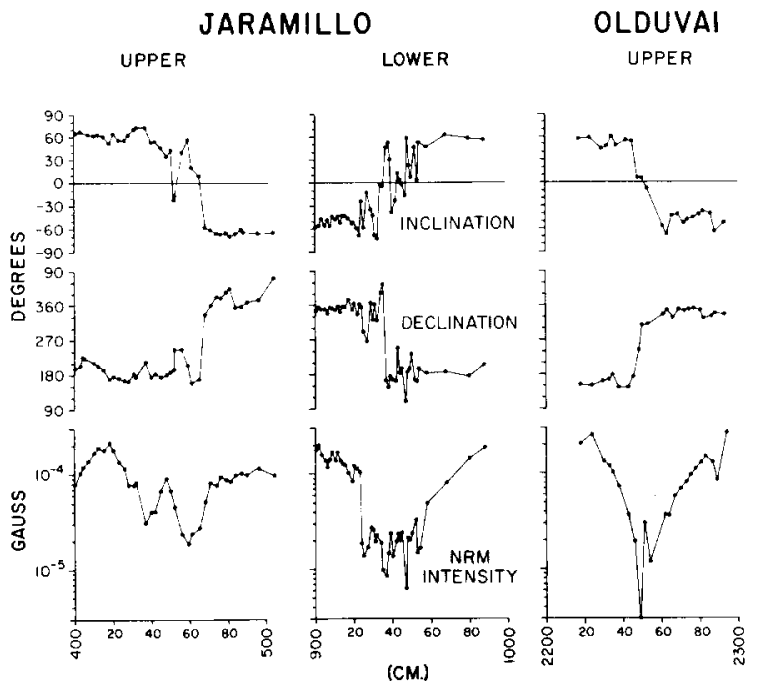

Fig. 5. Details of inclination, declination and intensity of magnetically cleaned remanence across the upper and lower Jaramillo, and the upper Olduvai polarity transitions (core RC14-14).

exhibit faint laminations. We, therefore, feel that bioturbation has not acted on this section of core to obscure the details of the reversal.

All three transitions have the following features in common: (1) intermediate directions of magnetization; (2) a pronounced drop of intensity of magnetization; (3) the drop in intensity of magnetization is coincident with the onset of the directional changes. The last observation is contrary to what we had previously thought [13].

The lower Jaramillo transition deserves further examination. The time taken for both intensity and direction of the field to reverse is approximately $4600 \mathrm{yr}$, based on the sedimentation rate of $8.6 \mathrm{~cm} /$ $1000 \mathrm{yr}$ inferred from the length of the Jaramillo event in this core. This value is in excellent agreement with other estimates of the time taken for field reversals to occur, which range from $1200 \mathrm{yr}$ to $4600 \mathrm{yr}$ [13-16]. However, the results contrast with those of Dunn et al. [17] who found that although the directional change occurred in about $4000 \mathrm{yr}$, the accompanying intensity variation took place over a period of some 10,000 yr.

It can be seen that in this record of the lower Jaramillo transition the intensity of magnetization decreases rapidly to a low value in a period of less than $1000 \mathrm{yr}$ and remains at a low value for a con- siderable time. An examination of the intensity changes which take place while the change in polarity is in progress reveals three cycles of intensity change with a period of about $1400 \mathrm{yr}$. The declination and inclination variations exhibit a similar periodicity. It can also be seen that a sharp change in declination occurs at the end of the second of these 1400-yr cycles, coincident with the polar shift between the hemispheres. The period of these movements is close to that usually associated with secular variation of the non-dipole field. These observations support the hypothesis that during the transition intervals the dipole field is weak, comparable in intensity to the non-dipole field.

\section{Changes in virtual geomagnetic pole position}

By using a deliberate adjustment to the paleo. magnetic data from this core, we are able to examine the movement of the virtual geomagnetic pole position during the reversal. In order to do this, the mean declination of the specimens prior to each reversal was determined. The mean declination was then set to $360^{\circ}$ or $180^{\circ}$ depending on the polarity. As justification of this step, we use the fact that average inclinations in the core agree with the axial dipole field inclination, so that it is reasonable to expect the mean core declinations to be those of the normal or reversed axial fields, also, provided no evidence of twisting of the core is found.

Figs. 6 and 7 show the motion of the VGP across each of the three polarity transitions examined. The movement of the VGP for the upper Olduvai polarity change (fig. 6) is straightforward, from a position centered on the north pole south through the Atlantic Ocean sector to the south polar regions. The upper Jaramillo transition seems to show slightly more detail. The VGP moves from the vicinity of the north pole, south across North America and west of South America, to the south polar regions where the path describes a distinct counter-clockwise loop before achieving a stable position near the south pole.

The greatest complexity is observed in the lower Jaramillo transition (fig. 7). The reversal starts in the south polar region. The VGP describes first a clockwise and then a counter-clockwise loop. It then enters the northern hemisphere moving northwards through 


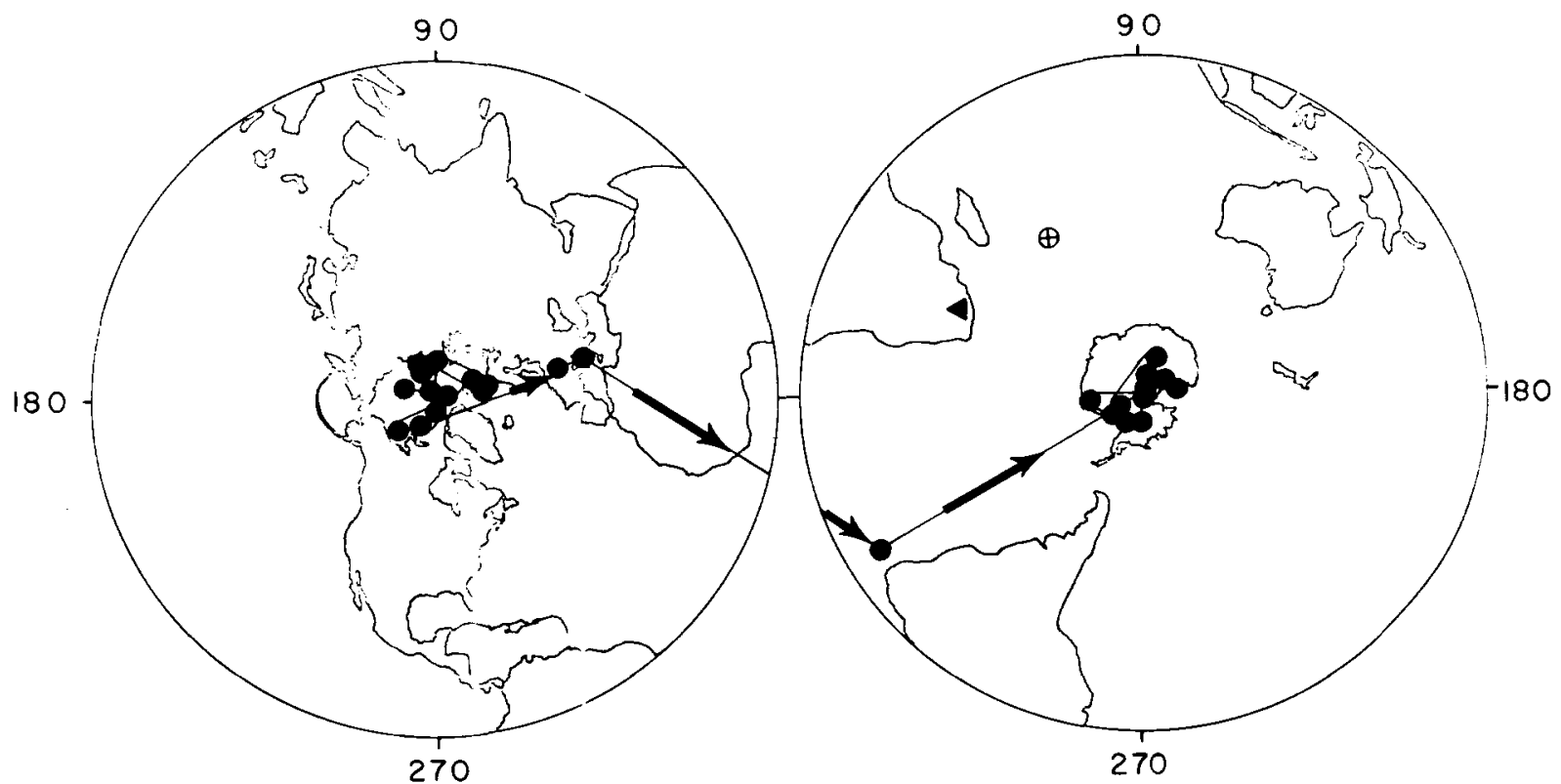

Fig. 6. Positions of VGP for upper Olduvai reversal (core RC14-14). VGP's calculated from cleaned remanent directions by suitable adjustment of declinations (see text). Location of core shown by circled cross.

the western Pacific. Before settling down, it traces out a clockwise loop in the northern hemisphere. These three loops are accompanied by the intensity variation described earlier.

\section{Discussion}

Various models describing field reversal have been proposed. They fall generally into two classes. The first of these [18] suggests that during the reversal the earth's dipole field dies away, leaving only the non-dipole field, then builds again with opposite polarity. Others, such as Creer and Ispir [19], have suggested that the field maintains dipolar characteristics during a polarity change. Furthermore, Creer and Ispir have presented evidence which suggested that the preferential path of the resultant dipole passes from one hemisphere to another through the Indian Ocean. Since core RC14-14 is situated in the Indian Ocean, (see fig. 6), it is ideally situated to test this hypothesis. None of the transition paths preserved in this core pass through the Indian Ocean. In addition, the three reversal paths each occur in different meridional quadrants: our data do not support Creer and Ispir's hypothesis, at least not for the three polarity changes examined here.
If the field remains dipolar during a change in polarity, one would expect that an intermediate direction of magnetization for the same transition from another position on the globe should yield a VGP position on the polar paths shown here. A single intermediate direction of magnetization is known that has a $\mathrm{K} / \mathrm{Ar}$ date that would associate it with the upper transition of the Jaramillo event ( $0.86 \mathrm{my}$ ). This was reported [20] from the type locality of the Jaramillo event from Jaramillo Creek, New Mexico. This lava yields a VGP situated in South Africa and is represented in fig. 7 by the triangle. Our data show that this position is about $90^{\circ}$ away from the VGP paths of both the upper and the lower reversal of the Jaramillo event. We conclude that the evidence does not support the model of a toppling dipole.

From the study of these polarity changes and, in particular, the transition at the base of the Jaramillo event, the following picture of field behavior during a polarity transition emerges. We believe that the intensity of the dipole field drops rapidly (fig. 5) to a low but non-zero value allowing the non-dipole field to predominate. This is reflected in the large looping excursions from the rotation axis seen in the VGP paths (fig. 7). Since both clockwise and anti-clockwise rotations of the VGP path are seen, it would appear that westward and eastward drift of the non-dipole field occurred $[21,22]$. 


\section{UPPER}

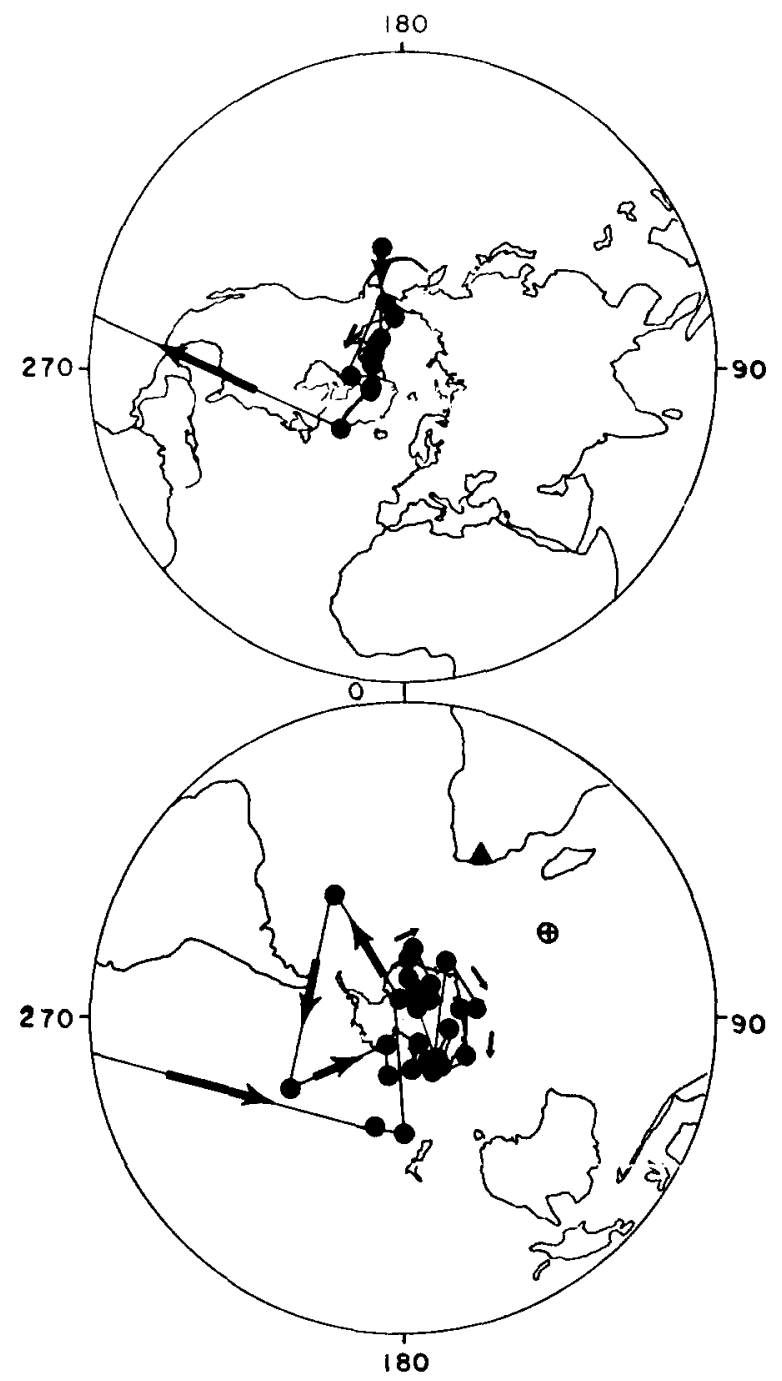

\section{LOWER}

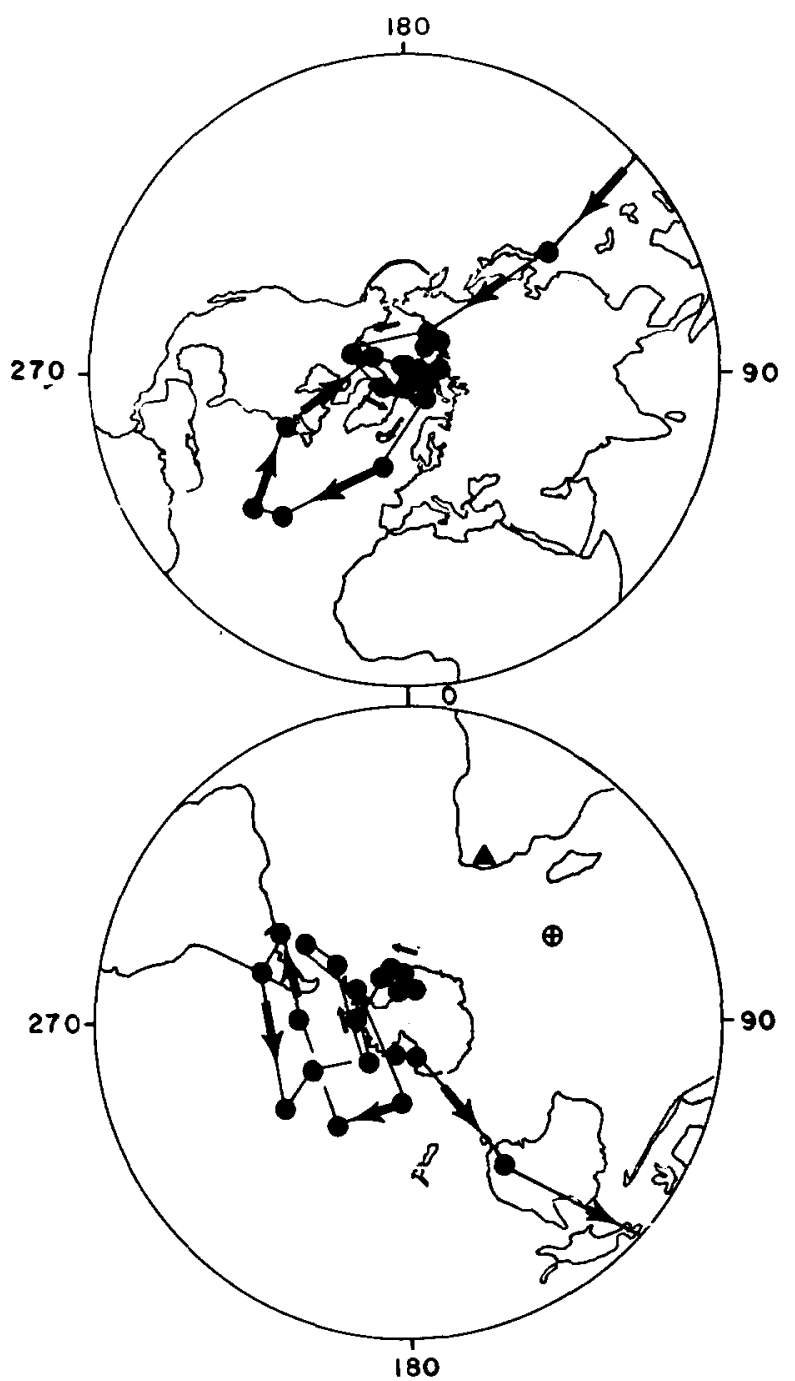

Fig. 7. Positions of VGP for upper and lower Jaramillo polarity transitions (core RC14-14). VGP's calculated from cleaned remanent directions by suitable adjustment of declinations (see text). VGP's for lower Jaramillo polarity transition are those resulting from a two-point running mean of original VGP's. Core location shown by circled cross. Position of VGP for intermediate direction from Jaramillo Creek, N. Mexico, dated at 0.86 my [20], is shown by solid triangle.

Both eastward and westward drift of the non-dipole field have also been inferred from the sense of VGP loops associated with the upper Miocene Steens Mountain polarity change [13] and those from Lake Windermere sediment cores covering the past 10,000 $\mathrm{yr}$ [23]. It is interesting to note that observatory records from Sitka, Alaska, indicate an eastward drift during the past sixty years, in contrast to the predominance of a westward direction of drift observed over most areas of the world for the past several hundred years $[22,24]$. Apparently, the direction of drift can vary with time as well as geographic location.

Although the excursions of the VGP's are large, 
they only rarely extend into equatorial latitudes. This may indicate that although the dipole field is much reduced, it is still of sufficient strength to keep the VGP's in middle and upper latitudes. The motion of the VGP from the southern to the northern hemisphere takes place at the intensity minimum at the end of the second 1400-yr cycle (during the lower Jaramillo reversal). At this point, the dipole field must have changed its polarity in a very rapid time, apparently of the order of a few hundred years.

The recovery of a sediment core which has a high deposition rate and contains magnetic polarity changes is uncommon. A core of some $70 \mathrm{~m}$ in length, longer even than this core RC14-14, the longest taken from a Lamont-Doherty research vessel, would be necessary to penetrate a sequence deposited at a high uniform rate $(\sim 10 \mathrm{~cm} / 1000 \mathrm{yr})$ spanning time from the present to the Brunhes/Matuyama boundary $(690,000$ yr). Apparently, other cores with missing upper sections will need to be studied to confirm some of our conclusions on field behavior during a polarity transition. These types of cores present such problems as the identification of other contained hiatuses and their duration. Although paleomagnetic observations on the sediment cores recovered in the Deep Sea Drilling Project have not yielded impressive magnetic stratigraphies, the great penetration of these cores would provide suitable material for this type of study. It would also be preferable to know the absolute azimuthal orientation of the core for detailed studies, although the present study shows that such analysis is possible without this information. This core orientation capability is not presently available on Lamont's coring apparatus.

\section{Acknowledgements}

We thank Drs. W.C. Pitman III, D. Ninkovich, and J. Weissel for critical evaluation of the manuscript. We also wish to thank Dr. J. Chute, the chief scientist on board the RV "Conrad", who was responsible for obtaining this remarkable core. Financial support for this research was provided by the Oceanographic Section of the National Science Foundation, Grants GA 30569 and GX 28671.

\section{References}

[1] J.D. Hays, T. Saito, N.D. Opdyke and L.H. Burckle, Pliocene-Pleistocene sediments of the Equatorical Pacific: their paleomagnetic, biostratigraphic, and climatic record, Geol. Soc. Am. Bull. 80 (1969) 1481.

[2] R. L $\phi$ vlie, W. Lowrie and M. Jacobs, Magnetic properties and mineralogy of four deep-sea cores, Earth Planet. Sci. Lett. 15 (1971) 157.

[3] T. Nagata, Magnetic properties of ferrimagnetic minerals of $\mathrm{Fe}-\mathrm{Ti}-\mathrm{O}$ system, Proc. Benedum Earth Magn. Symp. (1962) 69.

[4] M. Ozima, and E.E. Larson, Low and high temperature oxidation of titanomagnetite in relation to irreversible changes in the magnetic properties of submarine basalts, J. Geophys. Res. 75 (1970) 1003.

[5] M. Ozima and M. Ozima, Activation energy of unmixing of titanomaghemite, Phys. Earth Planet. Inter. 5 (1972) 87.

[6] K.M. Creer, J. Ibbetson and W. Drew, Activation energy of cation migration in titanomagnetites, Geophys. J. R. Astron. Soc. 19 (1970) 93.

[7] M.W. McElhinny, An improved method for demagnetizing rocks in alternating magnetic fields, Geophys. J. R. Astron. Soc. 10 (1966) 369.

[8] N.D. Opdyke, B. Glass, J.D. Hays and J. Foster, Paleomagnetic study of Antarctic deep-sea cores, Science 154 (1966) 349.

[9] J.D. Hays, Faunal extinctions and reversals of the earth's magnetic field, Geol. Soc. Am. Bull. 82 (1971) 2433.

[10] N.D. Opdyke, The Jaramillo Event as detected in oceanic cores, in: The Application of Modern Physics to the Earth and Planetary Interiors, S.K. Runcorn, ed. (Wiley-Interscience, London, 1969) 549.

[11] D. Ninkovich, N.D. Opdyke, B.C. Heezen and J.H. Foster, Paleomagnetic stratigraphy, rates of deposition and tephrachronology in North Pacific deep-sea sediments, Earth Planet. Sci. Lett. 1 (1966) 476.

[12] K. Kobayashi, K. Kitazawa, T. Kanaya and T. Sakai, Magnetic and micropaleontological study of deep-sea sediments from the west-central equatorial Pacific, Deep-Sea Res. 18 (1971) 1045.

[13] N.D. Watkins, Non-dipole behavior during an Upper Miocene geomagnetic polarity transition in Oregon, Geophys. J.R. Astron. Soc. 17 (1969) 121.

[14] N.D. Opdyke, Paleomagnetism of deep-sea cores, Rev. Geophys. Space Phys. 10 (1972) 213.

[15] M.W. McElhinny, Paleomagnetism and plate tectonics (Cambridge Univ. Press, Cambridge, 1973) 134.

[16] A. Cox and G.B. Dalrymple, Statistical analysis of geomagnetic reversal data and the precision of potassiumargon dating, J. Geophys. Res. 72 (1967) 2603.

[17] J.R. Dunn, M. Fuller, H. Ito and V.A. Schmidt, Paleomagnetic study of a reversal of the earth's magnetic field, Science 172 (1971) 840. 
[18] E. Bullard, Reversals of the earth's magnetic field, Phil. Trans. R. Soc. Lond. A263 (1968) 481.

[19] K.M. Creer and Y. Ispir, An interpretation of the behavior of the geomagnetic field during polarity transitions, Phys. Earth Planet. Inter. 2 (1970) 283.

[20] R. Doell and G.B. Dalrymple, Geomagnetic polarity epochs: a new polarity event and the age of the Brunhes/Matuyama boundary, Science 152 (1966) 1060.

[21] S.K. Runcorn, On the theory of the geomagnetic secular variation, Ann. Geophys. 15 (1959) 87.
[22] D.D. Skiles, A method of inferring the direction of drift of the geomagnetic field from paleomagnetic data, J. Geomag. Geoelectr. 22 (1970) 441.

[23] K.M. Creer, R. Thompson, L. Molyneux and F.J. Mackereth, Geomagnetic secular variation recorded in the stable magnetic remanence of Recent sediments, Earth Planet. Sci. Lett. 14 (1972) 115.

[24] T. Yukutake, The westward drift of the magnetic field of the earth, Bull. Earthq. Res. Inst. 40 (1962) 1. 